\title{
Nonseminomatous Extragonadal Germ Cell Tumor Presenting As Early Pericardial Tamponade
}

\author{
Taha Ahmed ${ }^{1}$, Talal Ahmad ${ }^{2}$, Samra Haroon Lodhi ${ }^{3}$, Tamoor Ahmed ${ }^{3}$ \\ 1. Internal Medicine, Cleveland Clinic Foundation, Cleveland, USA 2. Internal Medicine, Services Hospital, Lahore, PAK \\ 3. Internal Medicine, King Edward Medical University/Mayo Hospital, Lahore, PAK
}

Corresponding author: Taha Ahmed, tah227@uky.edu

\begin{abstract}
Multiple different types of mediastinal masses may be encountered on imaging techniques in symptomatic and asymptomatic patients. The most frequent mediastinal masses in adults are thymoma, lymphoma, thyroid masses, and germ cell tumors. Potential complications of these masses due to localized invasion include hemoptysis, post-obstructive pneumonia, and superior vena cava syndrome. Pericardial tamponade is usually secondary to pericarditis, trauma, infections, radiation, uremia, vascular diseases, and uremia. However, this report presents a case of a young patient who was found to have a large pericardial effusion and early signs of pericardial tamponade, which have not previously been reported as complications of extragonadal germ cell tumors, to the best of our knowledge.
\end{abstract}

Categories: Cardiology, Internal Medicine, Oncology

Keywords: nonsemonomatous, germ cell tumor, pericardial tamponde

\section{Introduction}

Male germ cell tumors (GCTs) usually arise from the testis; however, a small subset of them is of extragonadal origin. Extragonadal GCTs are rare and do not have a primary testicular involvement [1]. They are usually found along the midline of the body and are most common in the mediastinum, thymus, retroperitoneal organs, and pineal gland [2]. The exact histogenesis has not been elucidated, but is believed to be secondary to improper migration of germ cells along the urogenital ridge to the gonadal ridges during embryonic development. The clinical symptoms are nonspecific and vary according to the tumor location. We present an interesting case of a 28 -year-old male who presented with findings of pericardial effusion and tamponade secondary to an anterior mediastinal GCT compressing the right ventricle.

\section{Case Presentation}

Received 02/18/2020 Review began 02/24/2020 Review ended 02/27/2020 Published 02/28/2020

(c) Copyright 2020

Ahmed et al. This is an open access article distributed under the terms of the Creative Commons Attribution License CC-BY 4.0., which permits unrestricted use, distribution, and reproduction in any medium, provided the original author and source are credited.
A 28-year-old male presented with a one-week history of pleuritic chest pain, worsening shortness of breath, and non-productive cough. On physical examination, he was in distress and preferred sitting position with his arms elevated to avoid chest pain. Neck exam was positive for jugular venous distention, lungs were clear on auscultation, and cardiac examination showed muffled heart sounds. Vital signs on presentation revealed that he was hypotensive $(98 / 54 \mathrm{mmHg})$ with a heart rate of 102 beats per minute and afebrile. Electrocardiogram showed sinus tachycardia with low voltage complexes (Figure 1).

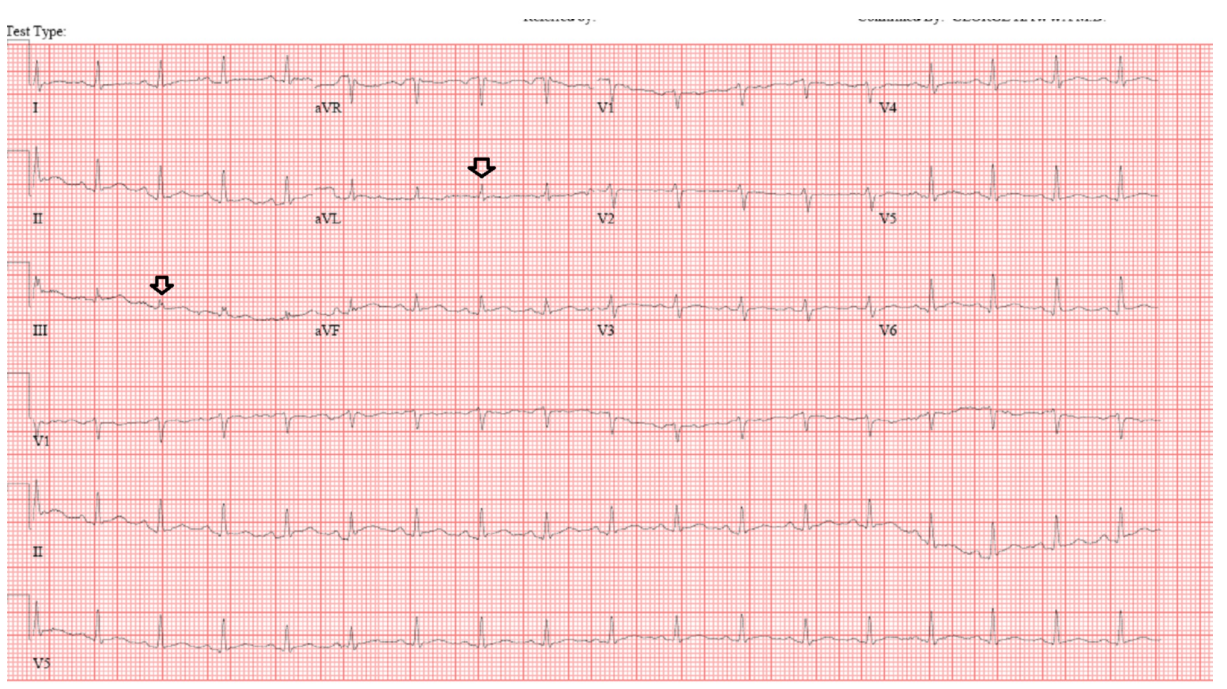




\section{Cureus}

FIGURE 1: Electrocardiogram showing low voltage QRS complexes

A chest $\mathrm{x}$-ray showed contour deformity in the right aspect of the mediastinum with a smooth rounded protuberance in the right perihilar region (Figure 2).

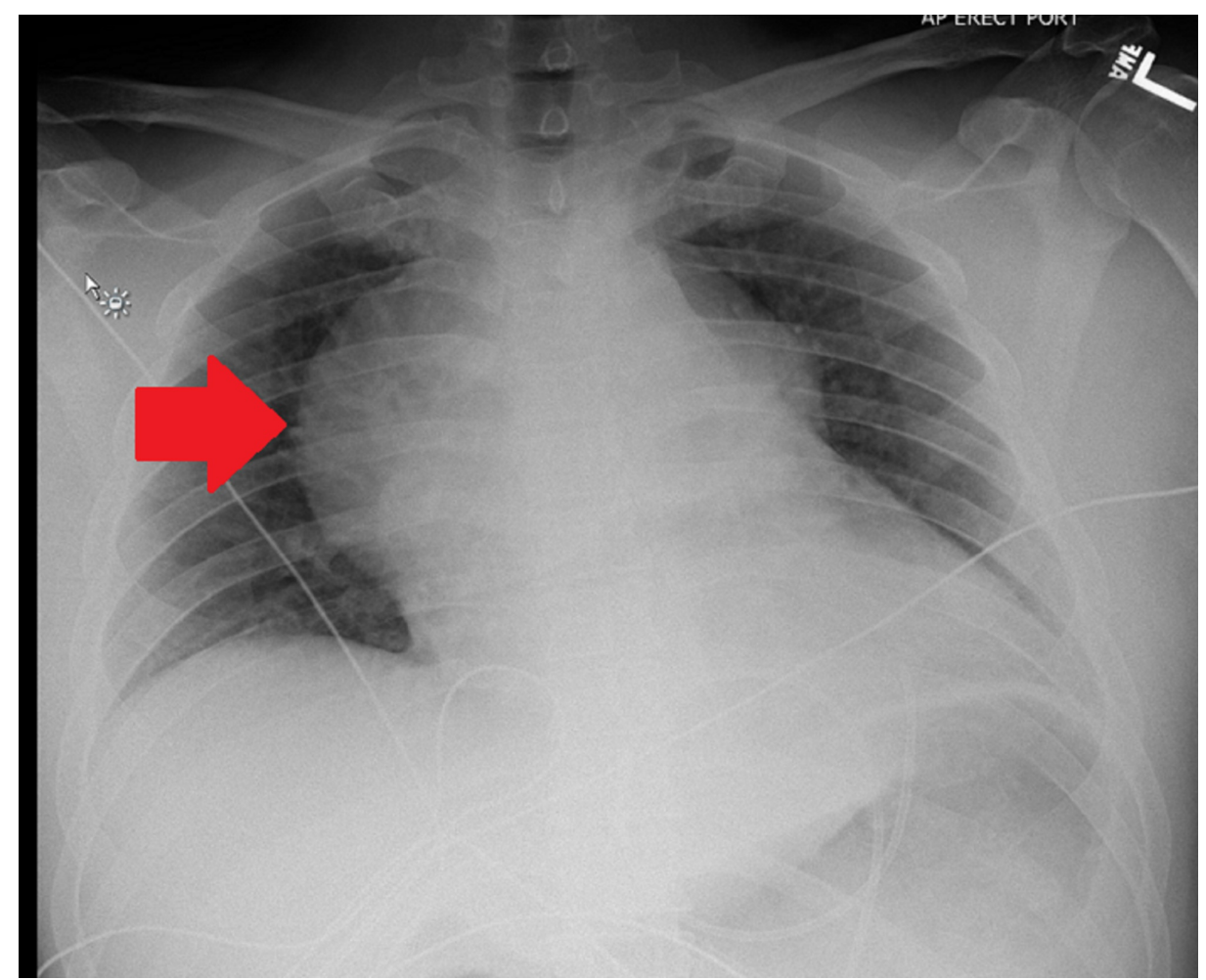

FIGURE 2: Chest X-ray showing smooth protuberance in the right perihilar region

D-dimer was elevated, and computed tomography (CT) of the chest was done which, although negative for a pulmonary embolus, revealed a large pericardial effusion and a heterogeneous anterior mediastinal mass (Figures 3, 4). 


\section{Cureus}

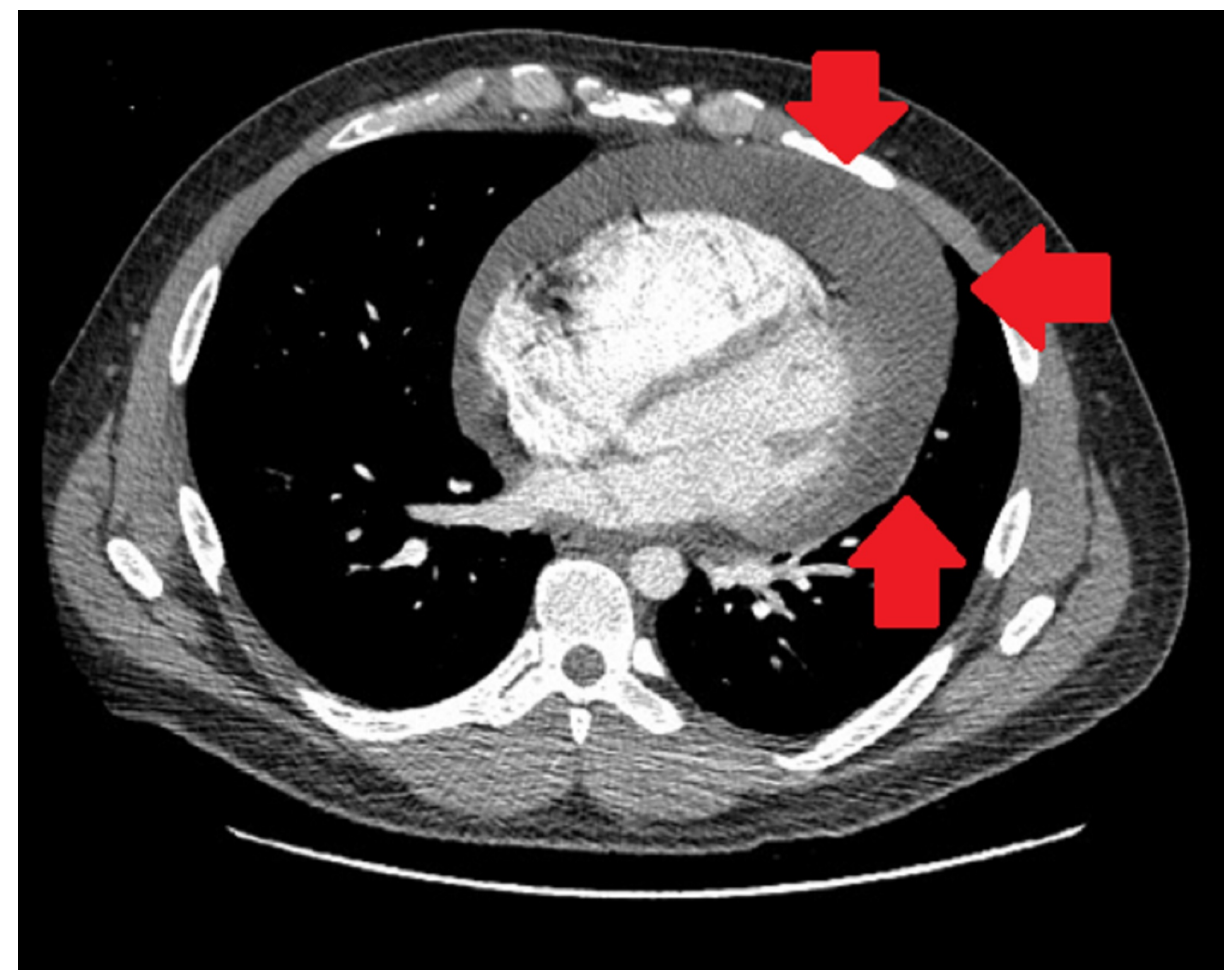

FIGURE 3: Computed tomography of the chest showing circumferential pericardial effusion and no significant pleural effusion

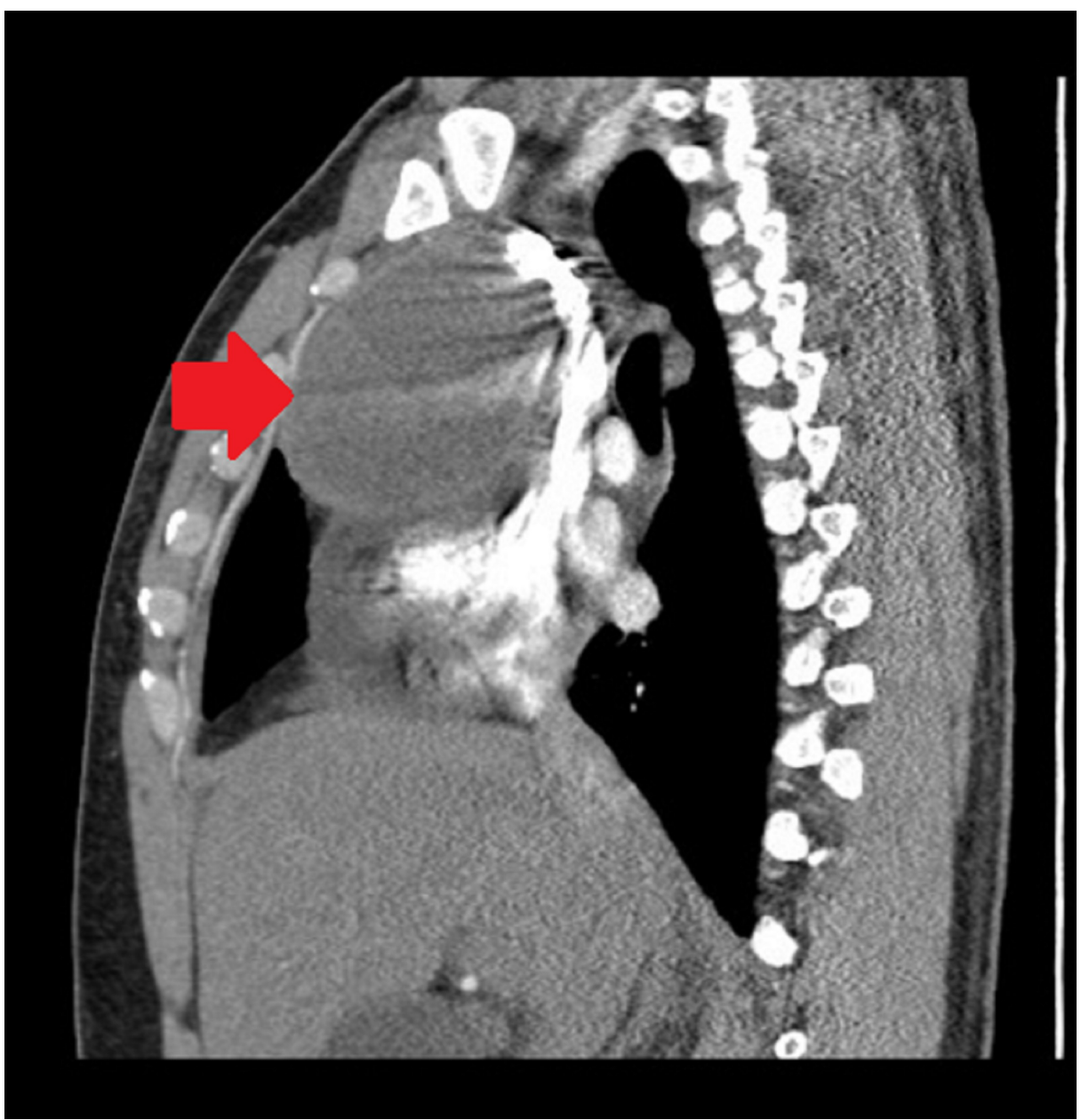


The patient was admitted to the intensive care unit (ICU) for further management. Bedside echocardiogram in the ICU showed a large circumferential pericardial effusion measuring $4 \mathrm{~cm}$ adjacent to both ventricles, inversion of the right atrium and right ventricle, and a large mediastinal mass partially compressing the base of the right ventricle (Video 1).

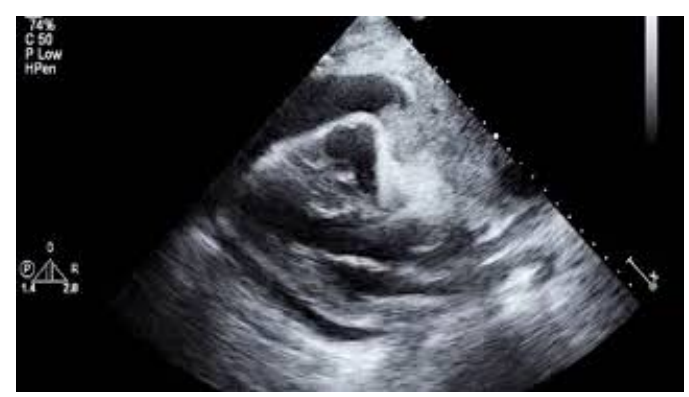

\section{VIDEO 1: Transthoracic echocardiogram showing circumferential pericardial effusion and a large mediastinal mass partially compressing the base of the right ventricle}

View video here: https://www.youtube.com/watch?v=47As2Y38BIQ

These findings were suggestive of early pericardial tamponade, and hence it was decided to drain the pericardial effusion percutaneously prior to performing a formal pericardial window. After percutaneous drainage of the pericardial effusion, right thoracoscopy was done with the placement of a pericardial window performed. Cytology samples from pericardial effusion and the pericardium were also sent.

On labs, alpha-fetoprotein (AFP) showed to be very high at 8,132 ng/ml (normal $<11 \mathrm{ng} / \mathrm{ml}$ ), lactate dehydrogenase $(\mathrm{LDH})$ 453U/L (normal=199-220 U/L), and beta-human chorionic gonadotropin (b-HCG) 46 $\mathrm{U} / \mathrm{L}$ (normal=4U/L). The pericardial fluid was positive for malignant cells. These results were highly suggestive of an extragonadal GCT, and a tissue biopsy of the mass was taken in the setting of these results. The biopsy results showed yolk sac tumor; CT abdomen and pelvis showed no intra-abdominal pelvic mass or lymphadenopathy.

The findings were discussed with the patient and his family, and they agreed with the initiation of chemotherapy and sperm banking. After sperm banking, the patient was started on platinum-based chemotherapy [3]. The patient got a five-day course of chemotherapy, the chest tube was removed, and he was discharged with a follow-up with the oncologist.

\section{Discussion}

Extragonadal nonseminomatous germ cell tumors (NSGCTs) primarily affect men during the third and fourth decades of life [4]. These tumors are more aggressive and have a worse prognosis than their pure seminoma counterpart [5]. Approximately 85\% of patients with mediastinal NSGCTs are symptomatic at the time of diagnosis, with chest pain, hemoptysis, cough, fever, or weight loss being the most common presenting symptoms. Superior vena cava syndrome or pericardial tamponade is occasionally present [6,7]. Our patient presented with cough, shortness of breath, and was in acute distress. He was subsequently found to have a mediastinal yolk sac tumor compressing the heart with pericardial effusion and early signs of cardiac tamponade on bedside echocardiography. Anterior mediastinal NSGCT presenting as early cardiac tamponade is rarely seen in clinical practice, but its early recognition and treatment by emergent pericardiocentesis can be life-saving as was done in our patient [8].

Tumor markers including APF, b-hCG, and LDH help in the diagnosis of these tumors, but the definitive diagnosis and treatment are based on the results of the biopsy of the tumor. Our patient had a high AFP and b-hCG with the tumor biopsy showing a yolk sac tumor. He was admitted under the care of the oncology and thoracic surgical services for emergent chemotherapy; the patient will eventually get four cycles of etoposide, ifosfamide, and cisplatin chemotherapy followed by resection of any residual disease with the goal of treatment as a complete cure [7,9].

\section{Conclusions}


The present case report shows that one of the major causes of anterior mediastinal masses, particularly in young adult males, is an extragonadal GCT. Our patient presented with features of hemodynamic compromise secondary to pericardial tamponade; it was found that an anterior mediastinal tumor was the cause behind it. In order to reach a prompt and accurate diagnosis, a thorough cardiac workup including the use of echocardiogram and CT scans are imminent. Pericardial tamponade as a result of a GCT is rare but if recognized early can be life-saving as demonstrated by our case. The ultimate management of the tumor involves platinum-based chemotherapy followed by complete resection.

\section{Additional Information \\ Disclosures}

Human subjects: Consent was obtained by all participants in this study. Conflicts of interest: In compliance with the ICMJE uniform disclosure form, all authors declare the following: Payment/services info: All authors have declared that no financial support was received from any organization for the submitted work. Financial relationships: All authors have declared that they have no financial relationships at present or within the previous three years with any organizations that might have an interest in the submitted work. Other relationships: The Abstract of this case was presented at the CHEST Annual Meeting 2018 as a Poster Presentation. The online publication is appropriately cited in the Case Presentation section.

\section{Acknowledgements}

The abstract of this case was presented at the CHEST Annual Meeting 2018 as a poster presentation

\section{References}

1. Bokemeyer C, Nichols CR, Droz JP, et al.: Extragonadal germ cell tumors of the mediastinum and retroperitoneum: results from an international analysis. J Clin Oncol. 2002, 20:1864-1873. 10.1200/JCO.2002.07.062

2. Albany C, Einhorn LH: Extragonadal germ cell tumors: clinical presentation and management . Curr Opin Oncol. 2013, 25:261-265. 10.1097/CCO.0b013e32835f085d

3. Ahmed T, Ahmed T, Khalid S, Khan S: Nonseminomatous germ cell tumor presenting as early pericardial tamponade. Chest. 2018, 154:314A. https://doi.org/10.1016/j.chest.2018.08.287

4. Nichols CR: Mediastinal germ cell tumors. Clinical features and biologic correlates . Chest. 1991, 99:472-479. 10.1378/chest.99.2.472

5. Liu Y, Wag Z, Peng ZM, Yu Y: Management of the primary malignant mediastinal germ cell tumors: experience with 54 patients. Diagn Pathol. 2014, 9:33. 10.1186/1746-1596-9-33

6. Karanth SS, Vaid AK, Batra S, Sharma D: Mediastinal germ cell tumor causing superior vena cava tumor thrombosis. BMJ Case Rep. 2015, 2015:bcr2014208356. 10.1136/bcr-2014-208356

7. Mishra S, Asa Majumdar SK, Sable M, Parida DK: Primary malignant mediastinal germ cell tumors: a single institutional experience. South Asian J Cancer. 2020, 9:27. 10.4103/sajc.sajc_47_19

8. Skelton WP IV, Mahtta D, Welniak S, Franke AJ, Dang LH: Pericardial effusion as an atypical initial presentation of extra-gonadal nonseminomatous germ cell tumor: a case report and literature review. Oxf Med Case Reports. 2018, 2018:omx097. 10.1093/omcr/omx097

9. Kesler KA, Rieger KM, Hammoud ZT, et al.: A 25-year single institution experience with surgery for primary mediastinal nonseminomatous germ cell tumors. Ann Thorac Surg. 2008, 85:371-378.

10.1016/j.athoracsur.2007.09.020 